\title{
Editorial: Sustaining Soil Carbon to Enhance Soil Health, Food, Nutritional Security, and Ecosystem Services
}

\author{
Somasundaram Jayaraman ${ }^{1 *}$, Nishant K. Sinha ${ }^{1}$, Sandeep Kumar ${ }^{2}$ and Ashok K. Patra ${ }^{1}$ \\ ${ }^{1}$ Division of Soil Physics, Indian Council of Agricultural Research (ICAR)-Indian Institute of Soil Science, Bhopal, India, \\ ${ }^{2}$ Department of Agronomy, Horticulture and Plant Science, South Dakota State University, Brookings, SD, United States
}

Keywords: soil carbon, soil health, climate change, food and nutritional security, ecosystem services, greenhouse gas emission

\section{Editorial on the Research Topic}

Sustaining Soil Carbon to Enhance Soil Health, Food, Nutritional Security, and Ecosystem Services

In 2050 the world population will reach $\sim 10$ billion, an increase of $30 \%$. According to the $\mathrm{UN}$, food insecurity is one of the greatest challenges facing us today. Soil is a precious natural resource, about $98 \%$ of our food-directly or indirectly-comes from soil (Dalal et al., 2021; Lal et al., 2021). Therefore, sustaining soil health/sustainable soil management (SSM) is essential in addressing food security and socio-economic and environmental issues. Soil is directly/indirectly

OPEN ACCESS

Approved by:

Stacy Michelle Philpott, University of California, Santa Cruz,

United States

*Correspondence:

Somasundaram Jayaraman somajayaraman@gmail.com

Specialty section:

This article was submitted to Agroecology and Ecosystem Services,

a section of the journal Frontiers in Sustainable Food Systems

Received: 15 September 2021 Accepted: 18 October 2021 Published: 08 November 2021

Citation:

Jayaraman S, Sinha NK, Kumar S and Patra AK (2021) Editorial: Sustaining Soil Carbon to Enhance Soil Health, Food, Nutritional Security, and Ecosystem Services.

Front. Sustain. Food Syst. 5:777495. doi: 10.3389/fsufs. 2021.777495 linked with more 5-7 out of 17 sustainable development goals (SDGs) (U.N, 2015). However, globally one-third of planet's soils are degraded and soils have lost about $25-75 \%$ soil organic carbon (SOC), which is otherwise vital for sustainable soil quality and food production systems. On the other hand, agricultural activities around the world contribute about $\sim 25 \%$ to the annual emissions of these greenhouse gases (GHGs). Thus, we need a sustainable soil management (SSM) practices to improve soil carbon, soil health, crop productivity, reverse land degradation and enhance ecosystem services (Somasundaram et al., 2020).

The difference between actual and potential crop yield is among the many things that contribute to food shortages, poverty, and malnutrition in many parts of the world. Moreover, we need both the quantity and quality of the food to sustain present and future generations, which depends on soil fertility/health. Researchers and policy makers have invested considerable interest in sustaining "soil quality/health." Notwithstanding their efforts, unprecedented nutrient mining and soil degradation continue to threaten sustainable production systems and ecosystem services (Dalal et al., 2021; Lal et al., 2021). In the coming decades, "soil resources" will remain the focal point of food production, nutritional security and environmental conservation research. It will also be essential for climate change adaptation and mitigation, the protection of biodiversity, ecosystem services, water quality, poverty alleviation, and sustainable development.

Thus, we hosted a special collection on "Sustaining Soil Carbon to Enhance Soil Health, Food, Nutritional Security, and Ecosystem Services." This Research Topic addressed these important issues and challenges to foster awareness on soil health, carbon sequestration food and nutritional security, and ecosystem services. Indeed, its pleasure to write an editorial remark on the special collection which to date has been viewed more than 53,000 worldwide (https://www.frontiersin.org/research-topics/11225/sustaining-soil-carbon-toenhance-soil-health-food-nutritional-security-and-ecosystem-services). In this special collection, 


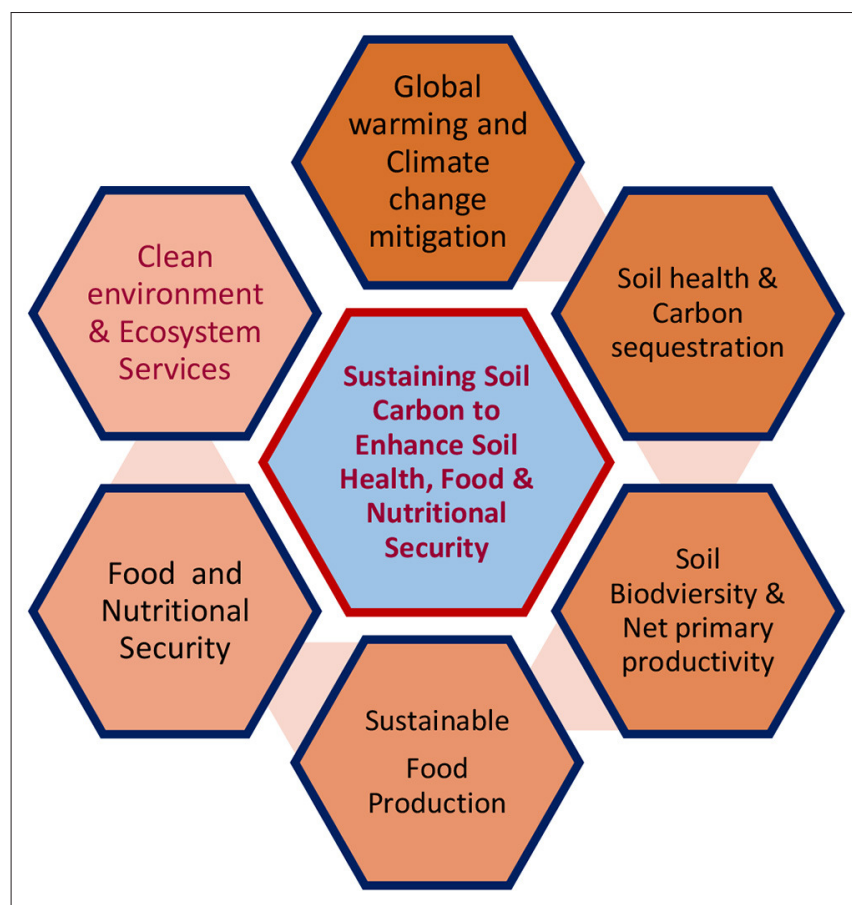

FIGURE 1 | Thematic concepts of different papers published in this Research Topics.

we have received 14 manuscripts out of which seven were accepted and published. This editorial note gives you a comprehensive overview of research papers published in this issue. Thematic concepts of different papers published in this special issue has been depicted in Figure 1.

Meier et al. published a paper on "Greenhouse Gas Emissions from Cropping and Grazed Pastures Are Similar: A Simulation Analysis in Australia." They reported that the agricultural sector has potential to provide greenhouse gas (GHG) mitigation by sequestering soil organic carbon (SOC). Replacing cropland with permanent pasture is one promising option to promote for its potential to sequester soil C. However, pastures frequently support livestock, which produce other GHG emissions that could negate the abatement from increased SOC. Crop yields, pasture growth rates and emissions of carbon dioxide $\left(\mathrm{CO}_{2}\right)$ and nitrous oxide $\left(\mathrm{N}_{2} \mathrm{O}\right)$ from the soil were simulated with the APSIM farming systems model. Livestock emissions were predicted using Australian GHG accounting emission factors. In this study, the SOC sequestered in the stocked permanent pastures was offset by emissions from livestock, and emissions from cropping scenarios were similar to or significantly less than those from the livestock scenarios. The research findings highlight that: (a) the importance of using net GHG abatement potentials from combined emissions rather than a single GHG abatement process when evaluating potential abatement practices, and (b) characteristics of different locations can alter the abatement potential of management practices.

Demenois et al. published a paper on "Barriers and Strategies to Boost Soil Carbon Sequestration in Agriculture." The authors have emphasized that the Paris Agreement calls for limiting global warming below $2^{\circ} \mathrm{C}$. The " 4 per 1,000 Initiative (4PT): Soils for food security and climate" was launched in 2015 to increase SOC sequestration with three main objectives: mitigation of climate change, adaptation to climate change, and improved food security. One of the challenges of the Initiative relates to its feasibility in contrasted biophysical, social and economic environments, questioning the adoption rate of required new practices. Results of participatory multistakeholder workshops held at France and Senegal revealed the predominance of social and economic barriers such as lack of knowledge or training, increased difficulties of fieldwork, workload, risk handling, funding and social pressure. Biophysical constraints such as limited potential of soil organic matter (SOM) storage or rainfall scarcity and variability appear more important. The authors have also identified actions to foster the sequestration of soil $\mathrm{C}$ urged for an improved policy context leading to innovations in land planning, stakeholder communication, demonstration facilities, capacity building or financial support. The authors concluded that actions to support the 4PT Initiative need to include a variety of stakeholders such as extension services, private sector, civil society, local institutions, policy makers, consumers, and not only farmers.

Wichern et al. published a paper on "Organic Amendments Alleviate Salinity Effects on Soil Microorganisms and Mineralisation Processes in Aerobic and Anaerobic Paddy Rice Soils." The authors have reported that sea-water level rise leads to increased saltwater intrusion causing soil salinity on arable land with negative effects on soil microbial processes. Organic amendments are known to reduce the effects of salinity on soil microorganisms, therefore positively influencing microbial activity and nutrient cycling. However, the extent of this effect in paddy rice soils under aerobic compared to anaerobic conditions is unknown. Two soils from Bangladesh were incubated with rice straw, manure or a manure-rice straw mixture at 50 and $100 \%$ water holding capacity $\left(25^{\circ} \mathrm{C}\right.$, 27 days). Microbial activity and biomass in particular fungi increased most strongly after rice straw addition and resulted in $\mathrm{N}$ immobilization independent of moisture level. Rice straw and manure alleviated the effects of salinity on microorganisms, which is due to higher $\mathrm{C}$ availability for soil microorganisms after amendment of organic materials. This allows them to produce osmolytes, counteracting the osmotic effects of increased salinity. The authors have also highlighted the importance of organic amendments application, such as rice straw to paddy soils under saline conditions to reduce negative effects on soil microbial processes, allowing them to maintain their major functions.

Page et al. published a review paper on "The Ability of Conservation Agriculture to Conserve Soil Organic Carbon and the Subsequent Impact on Soil Physical, Chemical, and Biological Properties and Yield." The world's agricultural systems will need to produce more food to meet the need of increasing population amid challenges of climate change and deterioration of natural resources. Agricultural system has the ability to preserve and store soil organic carbon (SOC), due to the pivotal role that this plays in maintaining soil physical, chemical, and biological properties and ultimately yield. This review examines 
the literature published worldwide over the last 30 years to assess the impact of one widely applied agricultural management system, conservation agriculture (CA), on its ability to maintain SOC and the subsequent impacts on soil physical, chemical and biological properties, and yield. The authors have reported that effects of CA on SOC worldwide are variable, with both increases and decreases observed, in regions where soil and climatic conditions are favorable for biomass production and where the system does not negatively impact yield, then CA can lead to higher amounts of SOC relative to conventionally managed systems. They concluded that farmers need access to a range of tools and resources to allow them to identify if the principles of CA to successfully overcome the agronomic, social and economic challenges that can be associated with its use and also for better benefits.

Stefanski et al. published a paper on "Potential Use of Biological Herbicides in a Circular Economy Context: A Sustainable Approach." Of late, synthetic herbicides' intense and disordered use has triggered severe contamination of soils and water bodies, causing damage to living organisms, including vegetal herbicide-resistance. Thus, biological herbicides, offer promising option addressing these problems, especially for sustainable weed management in both agricultural and natural resource management contexts. The search for culture media to serve as alternatives to the existing conventional synthetic media has focused on microalgae biomass. The natural properties of these organisms make them ideal raw materials for fermentative processes. Thus, this study was aimed to integrate bioprocesses producing bio-herbicidal extract using a submerged fermentation process. The authors found that microalgae could be used as a substrate for obtaining bioherbicides. The biocompounds produced in this study were relevant for pre- and post-emergence control of model plants (Cucumis sativus), with vigor indexes of up to $8.05 \%$ and herbicide-resistant plants (Conyza bonariensis) with phytotoxic damage of up to $100 \%$ after 15 days. The enzymes also showed synergistic action when acting together with microalgae and fungi, potentiating the control effect on weeds. Overall, the system integrated bioprocesses through agro-industrial effluent recovery and reuse, considered one of the promising economic viability mechanisms by enhancing the development of more sustainable technologies that promotes the principles of a circular economy.

Sharma et al. published a paper on "Responses of Soil Carbon Pools, Enzymatic Activity, and Crop Yields to Nitrogen and Straw Incorporation in a Rice-Wheat Cropping System in North-Western India." Fertilizer- $\mathrm{N}$ application and straw incorporation impacts crop productivity due to changes in total organic carbon (TOC), its labile pools and the soil enzymatic activity. A long-term field experiment was conducted (since $2010)$ to study the effect of fertilizer- $\mathrm{N}$ application $(0,90,120$, and $150 \mathrm{~kg} \mathrm{~N} \mathrm{ha-1)} \mathrm{and} \mathrm{rice} \mathrm{straw} \mathrm{(RS)} \mathrm{incorporation} \mathrm{(0,} \mathrm{5.0,}$ 7.5 , and $10 \mathrm{Mg} \mathrm{ha}^{-1}$ ) on crop yield, C input, TOC and its labile pools and soil enzymatic activity under rice (Oryza sativa
L.) - wheat (Triticum aestivum L.) cropping system (RWCS) in north-western India. Results demonstrated that fertilizer-N application and rice straw (RS) incorporation significantly increased the rice and wheat grain yield, compared with control (CK). However, the RS incorporation alone did not impact crop yields. The sustainable yield index (SYI) for wheat was significantly lower with RS incorporation alone as compared with the other treatments. For rice, SYI was significantly higher for RS7.5N120, and was non-significant compared with the RS10.0N120. The authors reported that annual total C input in soil plow layer $(0-15 \mathrm{~cm})$ under RWCS varied between 3.34 and $9.78 \mathrm{Mg} \mathrm{C} \mathrm{ha}{ }^{-1}$, which was higher by $4.4 \mathrm{Mg} \mathrm{C}$ $\mathrm{ha}^{-1} \mathrm{yr}^{-1}$ ( 2.3-times) in RS10.0, compared with CK. They concluded that the conjoint application of fertilizer- $\mathrm{N}$ and RS incorporation (RS10.0N150) significantly increased the TOC, water extractable organic $\mathrm{C}$, hot water $\mathrm{C}$, microbial biomass $\mathrm{C}$ and basal soil respiration due to increased soil enzymatic activity viz. dehydrogenase activity (DHA), fluorescein diacetate (FDA), and alkaline phosphatise (Alk-P).

Kumar and Sharma published a review paper on "Soil Salinity and Food Security in India." India will require around 311 million tons of food grains (cereals and pulses) during 2030 to feed around 1.43 billion people, and the requirement expectedly would further increase to 350 million tons by 2050 . This review paper highlights the possibility of area expansion under agriculture by restoring the degraded lands. Nearly 147 million ha of land is subjected to various kind of soil degradation, including 94 million ha from water erosion, 23 million ha from salinity/alkalinity/acidification, 14 million ha from water-logging/flooding, 9 million ha from wind erosion and 7 million ha from a combination of factors due to different forces. Government of India has fixed a target of restoring 26 million ha of degraded lands, including saltaffected soils, by the year 2030 to ensure food security for the people. Around 6.74 million ha area in the country is salt-affected. The Indian council of Agricultural Research (ICAR) and other research organizations have developed several innovative technologies/strategies and on-farm tested. Gypsum-based sodic soil reclamation, sub-surface drainage of water-logged saline lands, salt tolerant crop varieties and improved agroforestry techniques are some of the welladapted technologies in the country. This review paper highlights that the on-going consistent research efforts for the management and reclamation of such soils would hopefully continue ensuring food security and also need for policies favorable for implementation of reclamation technologies in the country.

We hope that readers will benefit from this Frontier's special collection.

\section{AUTHOR CONTRIBUTIONS}

All authors listed have made a substantial, direct and intellectual contribution to the work, and approved it for publication. 


\section{REFERENCES}

Dalal, R. C., Thornton, C. M., Allen, D. E., Owens, J. S, and Kopittke, P. M. (2021). Long-term land use change in Australia from native forest decreases all fractions of soil organic carbon, including resistant organic carbon, for cropping but not sown pasture. Agric. Ecosys. Environ. 311:107326. doi: 10.1016/j.agee.2021.107326

Lal, R., Bouma, J., Brevik, E., Dawson, L., Field, D. J., Glaser, B., et al. (2021). Soils and sustainable development goals of the United Nations (New York, USA): an IUSS perspective. Geoderma Reg. 25:e00398. doi: 10.1016/j.geodrs.2021.e0 0398

Somasundaram, J., Sinha, N. K., Dalal, R. C., Lal, R., Mohanty, M., Naorem, A. K., et al. (2020). No-till farming and conservation agriculture in South Asiaissues, challenges, prospects and benefits. Crit. Rev. Plant Sci. 39, 236-279. doi: $10.1080 / 07352689.2020 .1782069$

U.N (2015). Sustainable Development Goals: The 17 Goals. UN Dep. Econ. Soc. Aff. Sustain. Dev. Goals. Available online at: https://sdgs.un.org/goals (accessed September 12, 2021).
Conflict of Interest: The authors declare that the research was conducted in the absence of any commercial or financial relationships that could be construed as a potential conflict of interest.

Publisher's Note: All claims expressed in this article are solely those of the authors and do not necessarily represent those of their affiliated organizations, or those of the publisher, the editors and the reviewers. Any product that may be evaluated in this article, or claim that may be made by its manufacturer, is not guaranteed or endorsed by the publisher.

Copyright $\odot 2021$ Jayaraman, Sinha, Kumar and Patra. This is an open-access article distributed under the terms of the Creative Commons Attribution License (CC $B Y)$. The use, distribution or reproduction in other forums is permitted, provided the original author(s) and the copyright owner(s) are credited and that the original publication in this journal is cited, in accordance with accepted academic practice. No use, distribution or reproduction is permitted which does not comply with these terms. 